Brandeis $\left.\right|_{\text {urear }}$

brandeis.edu/j-caste
CASTE: A Global Journal on Social Exclusion

Vol. 1, No. 1, pp. 241-243

February 2020

ISSN 2639-4928

DOI: $10.26812 /$ caste.v1i1.135

\title{
Title: Gendering Caste: Through a Feminist Lens
}

\author{
Author: Uma Chakravarti
}

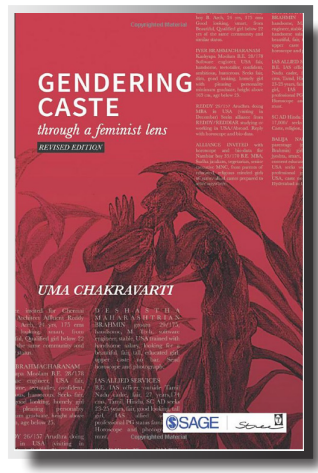

Publisher: Sage Publication: Year: 2018 (revised edition of 2003)

Reviewer: Indulata Prasad

Assistant Professor,

School of Social Transformation, Arizona State University, USA

E-mail: iprasad@asu.edu

The anti-Mandal agitation of 'upper castes' and the suicide of Dalit student Rohith Vemula bookended the revised edition of historian Uma Chakravarti's widely read book, Gendering caste: through a feminist lens. The book also commemorates Dr. B.R. Ambedkar's work on caste as it reiterates his position on endogamy as being critical to the 'unbroken reproduction of caste' for centuries and the perpetuation of a unique form of inequality in India. The revised edition's after word examines some key incidents in India around caste since the first publication of this book in 2003.It argues that even as caste and patriarchy in India remaining a state of flux, they retain their salience in both rural and urban areas, in the new millennium, due to the 'social silence' around the 'inherited legacies of practicing inequality.'

The primary concerns of Gendering Caste are fourfold. First, the text categorically rejects the tenacious dominant sociological theorisation of caste and rejects outright its capacity to capture the complex social order. It argues that overemphasising caste as an ideology and eliding the practice of caste from the purview of theorisation fails to grasp the complexity of the experience of caste-based oppression and obscures the privileged location in the hierarchical structure from where such theorisations take place. The text is among the first critical feminist interventions and push-backs on the dominant discourse of caste that views caste as a consensual rather than oppressive system that encompasses the economic, social, cultural, and political realm of Indian society, wherein 'caste ideology denies subjectivity to the Dalits by depriving them of dignity and personhood.' The text echoes marginalised theorisations of caste, as it demonstrates the necessity of 
extending the purview of caste to indicate that 'caste is not merely the opposition between pure and impure but at a more fundamental level it incorporates other kinds of oppositions such as domination and subordination, exploitation and oppression, based on unequal access to material resources.'

Second, the text demonstrates that the additive and disjointed model of investigating caste and gender is untenable, as caste, and gender by extension remain conjoint, with women 'at the heart of the conflict as protagonists and as victims, and also as aggressors in the new moment of constitutionally protected/granted rights to all citizens equally.' The text therefore makes the shift from the dominant nationalist paradigm of the 'status of women' concerning primarily upper-caste women by supplanting it with substantive questions of women's subordination as well as an investigation of the structures that make such subordination plausible. Of critical importance is the delineation of the historical roots of 'Brahmanical patriarchy' to demonstrate that the linkages between male dominance and upper-caste dominance is not a casual one but one that is 'more deeply and structurally linked.' It deeply impacts other forms of patriarchies. The historical tracing through the early societies alongside the ancient Hindu texts renders visible the evolution of caste-based patriarchal codes that developed in relationship with the formation of agrarian societies and was backed by state power. The complicity, 'consent' and subservience of women was achieved by patrolling upper-caste women's sexuality by both the state and community through the practice of endogamy, framed as tradition and through a system of reward and selective punishment. In fact, women in all respects were viewed as appendages to men. They were denied control over productive resources and autonomy in law. These factors are/were critical to maintaining the patriarchal structure as well as the silos of caste. The rationale being that 'the purity of women ensured the purity of caste and thus of the social order itself, not just in the existing society but in the future too.'

The third consideration of the text is the role of violence and the widely endemic culture of impunity around caste and gender-based violence that permeates every aspect of Indian society, including the state apparatus and governance. It draws much needed attention to the fact that while 'the law maintained its monopoly to punish crimes it did not displace the monopoly of dominant caste to rape, parade, and kill Dalit women.' By carefully examining case studies, the text demonstrates how sexual violence or extreme violence has been integral to caste domination and yet the law and the State refuse to recognise it. Instead, we see the proffering of depoliticised renderings of caste that overlook the similarity in the patterns of retaliatory attacks and the court acquittals when Dalits seek to claim their constitutionally guaranteed rights.

Lastly, the text draws attention to the role of institutionally sanctioned 'erasures' within the state apparatus to deny the historical nature of Dalit marginalisation in Indian society. Despite the existence of legal safeguards in the form of the Prevention of Atrocities Act (1989), the book examines several key legal cases wherein sexual violence against Dalit women was either not recognised and omitted or recorded as a legitimate response of the dominant caste, resulting in acquittals. The courts failed to recognize that the 'dominant castes' attempt to retain monopoly of the law is a feature 
of caste domination.' This demonstrates that even as the State continues to be an important site for realising constitutionally guaranteed rights for Dalits, it continues to fail Dalits by tendering these acts of violence as pertaining to conflict over resources, or stemming from personal or politically motivated reasons, among others.

Written for a wide audience, the book draws on vast and often diverse resources, ranging from historical and religious texts to sociological and anthropological literature. In tracing caste through the pre-colonial, colonial, and post-colonial eras and into the new millennium, Gendering Caste is an excellent primer on caste and gender as bulwarks of Indian society and the role of the State in maintaining hierarchies. But above all, by critically analyzing key events in India, Gendering Caste drives home the importance of undertaking the intellectual task of unmasking popular tropes on caste to uncover it sentanglements with gender and sexuality. As Chakravarti notes, 'The task of unraveling the relationship between caste and gender - of gendering the caste system - is even more difficult than recognising their workings individually because the whole weight of domestic ideology is against such a recognition.' 